\title{
Hyaluronic acid levels are increased in complicated parapneumonic pleural effusions
}

\author{
T. Zaga1, D. Makris¹, I. Tsilioni1, T. Kiropoulos¹, S. Oikonomidi1, \\ A. Damianos², K.I. Gourgoulianis ${ }^{1}$
}

ABSTRACT: Hyaluronic acid levels are increased in complicated parapneumonic pleural effusions. T. Zaga, D. Makris, I. Tsilioni, T. Kiropoulos, S. Oikonomidi, A. Damianos, K.I. Gourgoulianis.

Background and Aim. Hyaluronic acid (HA) is a component of extracellular matrix and may play a role in the pleural inflammation which is implicated in parapneumonic effusions. The aim of the current study was to investigate HA levels in serum and pleura in patients with parapneumonic effusions.

Methods. We prospectively studied pleural and serum levels of $\mathrm{HA}$ in 58 patients with pleural effusions due to infection (complicated and uncomplicated parapneumonic effusions), malignant effusions and transudative effusions due to congestive heart failure. In addition to HA, TNF- $\alpha$ and IL-1 $\beta$ levels were determined in pleural fluid and serum by ELISA.
Results. The median \pm SD HA levels $(\mathrm{pg} / \mathrm{ml})$ in pleural fluid of patients with complicated effusions $(39.058 \pm 11.208)$ were significantly increased $(p<0.005)$, compared to those with uncomplicated parapneumonic effusions $(11.230 \pm 1.969)$, malignant effusions $(10.837 \pm 4.803)$ or congestive heart failure $(5.392 \pm 3.133)$. There was no correlation between pleural fluid and serum HA values. Pleural fluid TNF- $\alpha$ levels $(146 \pm 127 \mathrm{pg} / \mathrm{mL})$ and IL-1 $\beta$ levels $(133.4 \pm 156 \mathrm{pg} / \mathrm{mL})$ were significantly higher in patients with complicated parapneumonic effusions compared to patients with other types of effusion $(p<0.05)$. No significant association between HA and TNF- $\alpha$ or IL-1 $\beta$ was found.

Conclusions. HA may play a significant role in the inflammatory process which characterises exudative infectious pleuritis. Further investigation might reveal whether $\mathrm{HA}$ is a useful marker in the management of parapneumonic effusions. Monaldi Arch Chest Dis 2011; 75: 3, 167-171.

Keywords: Hyaluronic acid, TNF- $\alpha, I L-1 \beta$, Parapneumonic pleural effusions, Extracellular matrix, Pleural inflammation.

1 Respiratory Department, University Hospital of Larissa,

2 General Hospital “Amalia Fleming”, Athens, Greece.

Correspondence: Mrs Irene Tsilioni - Respiratory Medicine Department, University of Thessaly Medical School, University Hospital of Larissa, Larissa 41110,Greece; E-mail: irinitsilioni@hotmail.com

\section{Introduction}

Hyaluronic acid (HA) is a member of glycosaminoglycan family which is implicated in many cell functions, such as cell growth, locomotion and tumor metastasis [1-5]. HA is widely distributed in connective tissues and serous membranes. HA in pleural fluid originates in the mesothelial cells and pleural tissue [1]. Notably, former studies reported increased HA levels can be found in malignant mesothelioma pleuritis and thus, HA was suggested to be useful as a biomarker related to the course of this malignant disease [6-8].

However, HA presents proinflammatory activity as well and functions as an important constituent of the extracellular matrix $[9,10]$. In line with this, a previous investigation showed that HA levels might be increased in patients with benign inflammatory diseases [11]. Previous studies showed that synovial cells from patients with rheumatoid arthritis (RA) produced larger quantities of HA than synovials cells from healthy persons, and it was suggested that is stimulated by Tu- mour Necrosis Factor- $\alpha$ (TNF- $\alpha$ ) and Interleukin$1 \beta$ (IL-1 $\beta$ ), both pivotal mediators of rheumatoid joint inflammation and destruction [12]. However, the role of HA in pleural effusions due to infectious causes is not known. Data regarding the levels of HA in parapneumonic effusions is limited.

In this respect, we aimed to study HA levels in parapneumonic effusions. We hypothesised that HA may be increased in the pleural fluid due to parapneumonic effusions. Secondly, we sought to investigate whether HA levels correlated with the levels of TNF- $\alpha$ and IL-1 $\beta$ which have been suggested to play a role in HA production.

\section{Methods}

This is an observational prospective study that included all consecutive patients who were admitted with pleural effusion at University Hospital of Larissa and General Hospital "Fleming" of Athens between February 2006 and December 2007, if they fulfilled the following criteria: a) no use of antibiotics, fibrinolytics or chemotherapeutics dur- 
ing the last 14 days before inclusion and b) stable respiratory status, c) stable haemodynamic condition d) absence of severe bleeding diathesis. Pleural fluid and serum samples obtained at baseline by thoracentesis and before the institution of antibiotic treatment.

\section{Definitions}

Pleural effusions were characterised as exudates and transudates according to Light's criteria [13]. Patients with complicated parapneumonic effusions and uncomplicated parapneumonic effusions fulfilled the criteria for diagnosis of parapneumonic effusions [14]. Parapneumonic pleural effusions were neutrophilic effusions associated with clinical and radiological signs consistent with pneumonia. The classification of parapneumonic effusions into uncomplicated, complicated and empyemas was based on the BTS guidelines [15]. Briefly, uncomplicated parapneumonic effusions successfully resolved with antibiotics alone. These effusions were identified by non-purulent pleural fluid, negative microbiological studies in pleural fluid, pleural fluid $\mathrm{pH}>7.2$, pleural fluid LDH $<1000 \mathrm{IU} / \mathrm{L}) 1$ and fluid glucose $>2.2 \mathrm{mM}$. Complicated parapneumonic effusions referred to those non purulent-appearing effusions that did not resolve without chest tube or any other drainage method. These effusions met at least one of the following criteria: (i) an inadequate clinical response to antibiotics treatment alone (i.e. persistent fever, pain or increased effusions) with resolution after tube drainage; (ii) a progression of the effusion to loculation or fibrothorax; (iii) pleural fluid $\mathrm{pH}$ < 7.2; (iv) pleural fluid LDH > $1000 \mathrm{IU} / \mathrm{L}$ ) and (v) pleural fluid glucose $<2.2 \mathrm{mM}$. Finally, empyema was defined as a condition in which the diagnostic thoracocentesis yielded gross pus, or a positive Gram stain or bacterial culture of the pleural effusion. Diagnosis of malignant pleural effusions was based on the demonstration of malignant cells on cytologic examination or in biopsy specimen or histologically proven primary lung malignancy with the exclusion of any other cause of pleural effusion.

\section{Biochemistry and cytology of the fluid}

Samples were immediately analysed for $\mathrm{pH}$ following the anaerobically procedure for obtaining samples. Total cells count, differential cell counts, total protein, glucose and LDH were measured in pleural fluid and serum. Pleural fluid and serum samples were centrifuged at $1500 \mathrm{~g}$ for 15 minutes and supernatant from each sample was stored at $-80^{\circ}$ to measure HA, IL- $1 \beta$ and TNF- $\alpha$.

\section{Cytokines assays}

HA, IL-1 $\beta$ and TNF- $\alpha$ in supernatant of the samples were measured by using ELISA (Biosource for HA, TNF- $\alpha$ and R \& D systems for IL-1 $\beta$ ).

\section{Statistical analysis}

Data are reported as medians. Data between groups were compared using the chi-square test or nonparametric tests as appropriate. A value of $p<0.05$ was considered statistically significant. Analysis was performed using the statistical software SPSS 15.0.

\section{Results}

The study population comprised 58 patients (20 women, 38 men). Baseline characteristics of participants are presented in table 1 and pleural fluid characteristics are shown in table 2. There were 22 malignant pleural effusions, 24 parapneumonic effusions (complicated-empyema $n=12$, uncomplicated $n=12$ ) and 12 transudates due to congestive heart failure. Five patients with lung cancer died after six months.

\section{Hyaluronic Acid levels in serum and pleura}

HA levels in the pleural fluid are presented in Figure 1. HA values in patients with complicated parapneumonic effusion $(39.058 \pm 11.208 \mathrm{pg} / \mathrm{mL})$ were significantly increased compared to patients with other effusions types such as transudates $(5.392 \pm 3.133 \mathrm{pg} / \mathrm{mL})$, lung cancer $(10.837 \pm 4.803$ $\mathrm{pg} / \mathrm{mL}$ ) and uncomplicated parapneumonic effusions $(11.230 \pm 1.969 \mathrm{pg} / \mathrm{mL})$. HA levels in uncomplicated parapneumonic effusions were not different compared to lung cancer and transudates, the difference between HA levels in transudates and lung cancer was significant $(p=0.05)$.

HA serum levels in patients with complicated parapneumonic effusions were $118 \pm 64.33 \mathrm{pg} / \mathrm{mL}$, in patients with uncomplicated parapneumonic effusion in patients with uncomplicated parapneumonic effusions were $13.52 \pm 15.30 \mathrm{pg} / \mathrm{mL}$, in patients with lung cancer were $87.72 \pm 64 \mathrm{pg} / \mathrm{mL}$ and in patients with transudate were $386.8 \pm 321.8$ $\mathrm{pg} / \mathrm{mL}$. There was no correlation between HA levels in serum and pleural fluid.

\section{TNF- $\alpha$ in serum and pleura}

TNF- $\alpha$ levels in the pleural fluid are presented in Figure 2. TNF- $\alpha$ values in patients with complicated parapneumonic effusion (146.3 \pm 127.8 $\mathrm{pg} / \mathrm{mL}$ ) were significantly increased compared to patients with other effusions types such as transudates $(18.30 \pm 10.88 \mathrm{pg} / \mathrm{mL})$, lung cancer $(30.85 \pm 19.96$

Table 1. - Baseline characteristics of all 58 participants

Age, years

$69.8 \pm 36.7$

Gender male/female, $\mathrm{n}$

$38 / 20$

Type of effusion

Congestive heart failure

$12(21 \%)$

Lung cancer

$22(37 \%)$

Complicated parapneumonic effusions

$12(37 \%)$

Uncomplicated parapneumonic effusions 
Table 2. - Characteristics of pleural fluid in various types of effusion

Parapneumonic effusions

\begin{tabular}{lcccc}
\hline & $\begin{array}{c}\text { Lung cancer } \\
(\mathbf{n = 2 2})\end{array}$ & $\begin{array}{c}\text { Transudates } \\
(\mathbf{n = 1 2})\end{array}$ & $\begin{array}{c}\text { Complicated - Empyema } \\
(\mathbf{n = 1 2})\end{array}$ & $\begin{array}{c}\text { Uncomplicated } \\
(\mathbf{n}=\mathbf{1 2})\end{array}$ \\
\hline Total cell count (cells/mm 3$)$ & $2044 \pm 3042$ & $422 \pm 272.3$ & $2077 \pm 2653$ & $1981 \pm 1911$ \\
Neutrophils\% & $13.57 \pm 12.58$ & $24.5 \pm 34.56$ & $68.23 \pm 24.63$ & $52.86 \pm 18.97$ \\
Lymphocytes\% & $61.62 \pm 23.02$ & $58.40 \pm 30.62$ & $16.58 \pm 15.28$ & $32.43 \pm 22.23$ \\
\hline Glucose (mg/dL) & $124.3 \pm 46.82$ & $153.0 \pm 64.56$ & $2.71 \pm 1.4$ & $22.2 \pm 13.49$ \\
\hline LDH U/L & $1131 \pm 2119$ & $186.2 \pm 78.09$ & $4036 \pm 899$ & $765.9 \pm 533.8$ \\
\hline pH & $7.40 \pm 7.35$ & $7.46 \pm 7.37$ & $7.14 \pm 0.078$ & $7.41 \pm 7.33$ \\
\hline Protein (g/dL) & $4.167 \pm 0.8974$ & $2.5 \pm 0.6$ & $4.36 \pm 0.67$ & $4.5 \pm 0.8$ \\
\hline
\end{tabular}

Data are presented as median $\pm \mathrm{SD}$.

$\mathrm{pg} / \mathrm{mL})$ and uncomplicated parapneumonic effusion $(31.87 \pm 16.42 \mathrm{pg} / \mathrm{mL})$. TNF- $\alpha$ levels in uncomplicated parapneumonic effusions were not different compared to lung cancer and transudates $(p=0.05)$.

There were no differences between TNF- $\alpha$ levels in serum in patients with complicated parapneumonic effusion (4.678 pg/mL), lung cancer, $(16.81 \pm 10.88 \mathrm{pg} / \mathrm{mL})$, transudates $(16.92 \pm 7.212$ $\mathrm{pg} / \mathrm{mL}$ ) and uncomplicated parapneumonic effusion $(14.58 \mathrm{pg} / \mathrm{mL})$. There was no correlation between TNF- $\alpha$ levels in serum and pleural fluid. No correlation was found between PF-HA and TNF- $\alpha$, levels.

\section{IL-1 $\beta$ in serum and pleura}

IL-1 $\beta$ levels in the pleural fluid are presented in Figure 3. IL-1 $\beta$ values in patients with complicated parapneumonic effusion $(133.4 \pm 156.2 \mathrm{pg} / \mathrm{mL})$

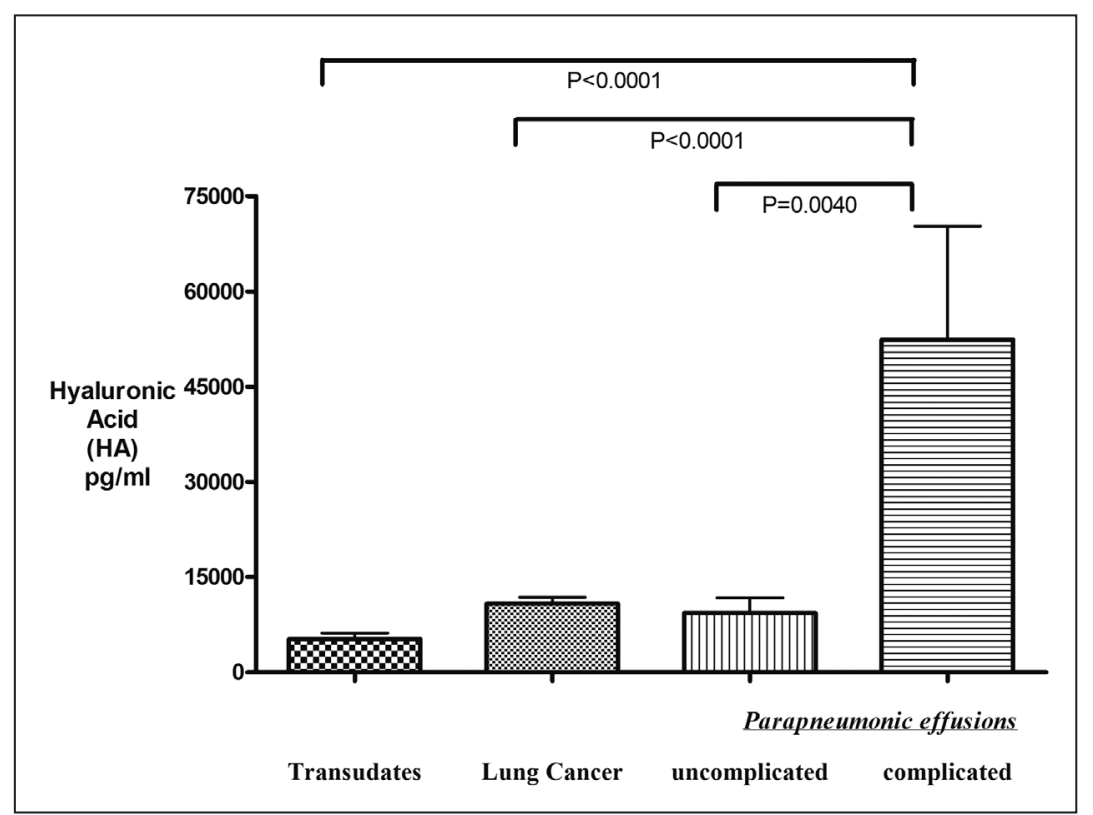

Fig. 1. - Hyaluronic acid levels in the pleural fluid of different types of effusions; p-values represents differences between empyema and other types of effusions. were significantly increased compared to patients with transudates $(8.44 \pm 3.550 \mathrm{pg} / \mathrm{mL})$, lung cancer $(18.36 \pm 35.46 \mathrm{pg} / \mathrm{mL})$ and uncomplicated parapneumonic effusions $(39.95 \pm 71.84 \mathrm{pg} / \mathrm{mL})$. IL-1 $\beta$ levels in uncomplicated parapneumonic effusions were not different compared to lung cancer and transudates $(p=0.05)$.

There were no significant differences between serum IL-1 $\beta$ levels in complicated parapneumonic effusion $(4.67 \mathrm{pg} / \mathrm{mL})$, lung cancer, $(8.220 \pm 5.505$ $\mathrm{pg} / \mathrm{mL})$, transudates $(13.47 \mathrm{pg} / \mathrm{mL})$ and uncomplicated parapneumonic effusions (14.69 pg/mL). There was no correlation between IL-1 $\beta$ levels in serum and pleural fluid. In addition, no correlation was found between PF-HA and TNF- $\alpha$, levels.

\section{Discussion}

The present study showed that HA pleural fluid levels in complicated parapneumonic effusions were significantly higher compared to transudates or other types of exudative pleural effusions including malignant effusions and uncomplicated parapneumonic effusions.

Our study provides novel evidence suggesting that HA levels are significantly increased in complicated parapneumonic effusions. Previous investigations have shown that increased HA levels in pleural fluid may be suggestive of malignant mesothelioma [7] or may be augmented in benign diseases such as rheumatoid arthritis [7, 12]. However, data on pleural effusions of infectious origin are sparse [12]. Furthermore, our findings suggest that in contrast to pleural fluid levels, serum HA levels were not different between parapneumonic effusions and 


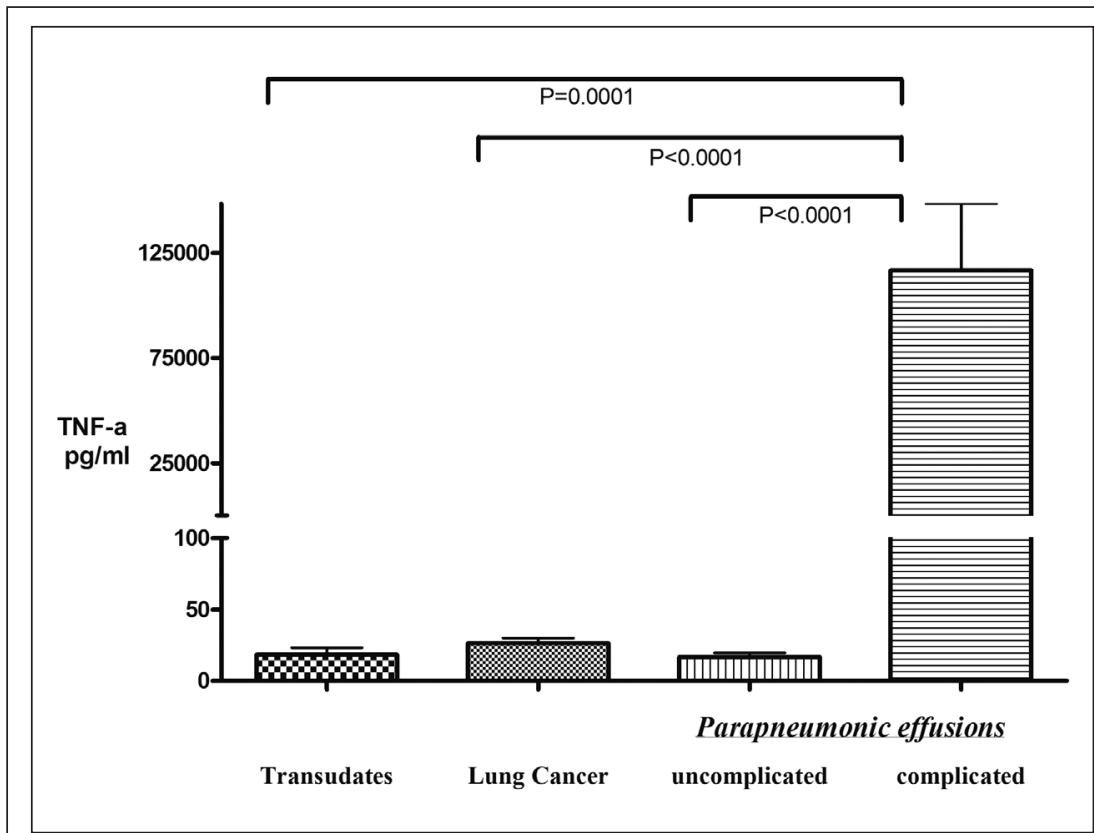

Fig. 2. - TNF- $\alpha$ levels in the pleural fluid of different types of effusions; p-value represents differences between empyema and other types of effusions.

other types of pleuritis. In this respect, HA production might be locally increased, at the site of inflammation, as part of the defensive mechanism of the extracellular matrix against infection and therefore HA levels might play a notable role in clinical course of empyema $[16,12]$.

HA is produced by the pleural mesothelial cells which are dynamic cells producing several other cytokines such as chemotactic-cytokines [9, 21]. HA may participate in the regulation of inflammation via regulation of production of proinflammatory cytokines, leukocyte chemotaxis and

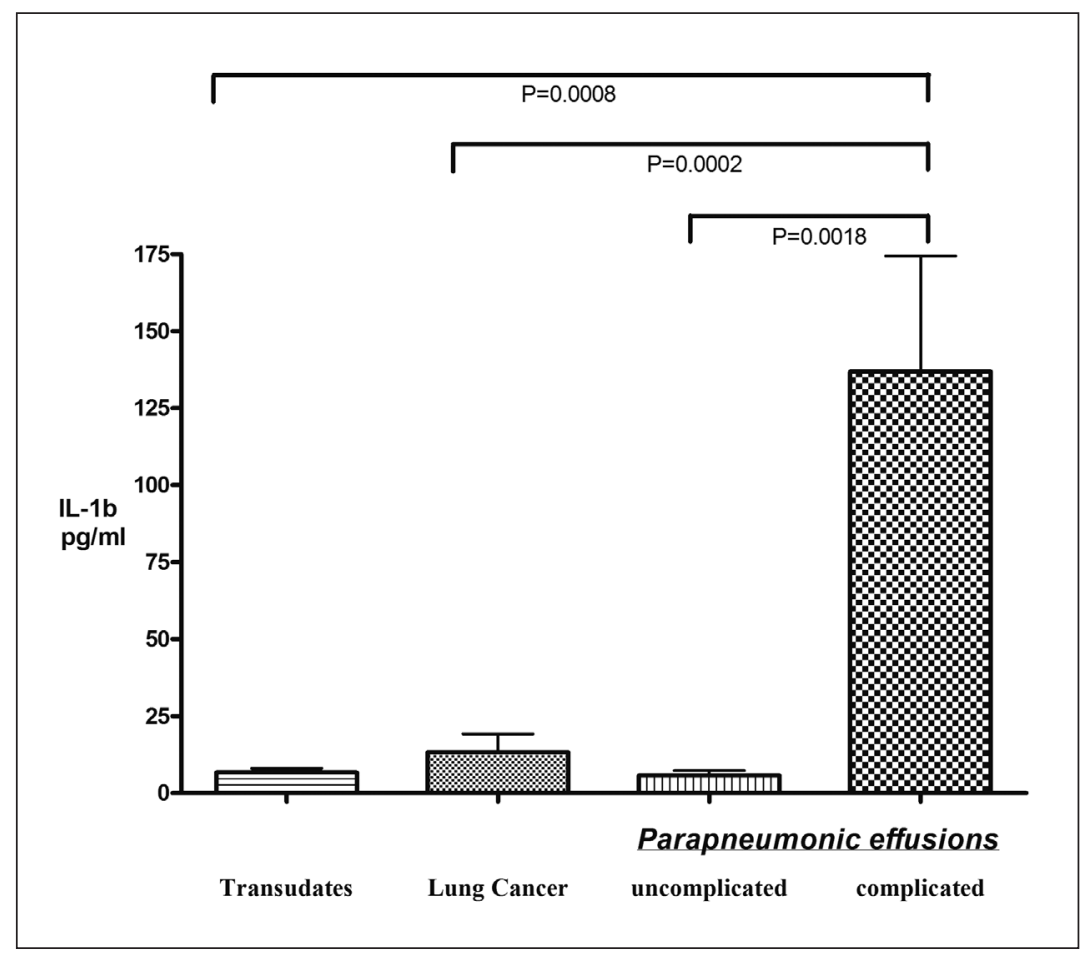

Fig. 3. - IL-1 $\beta$ levels in the pleural fluid of different types of effusions; p-value represents differences between empyema and other types of effusions. macrophage phagocytes [6-8, 22]. Recent evidence indicates that HA based cables, formed by stressed cells, are able to bind CD44 containing inflammatory cells and, in this way, to engage leucocytes recruited to the tissues by an inflammatory stimulus [1820]. Therefore, HA levels in severe inflammatory states such as pleural complicated effusions may be upregulated and in this respect may be increased in pleura. However, whether HA could be a therapeutic target incorporated in the management of complicated parapneumonic effusions remains to be investigated [16].

Previous investigations in rheumatoid arthritis that included synovial cell lines suggest that HA levels might be controlled by proinflammatory cytokines such as TNF- $\alpha$, IL-1 $\beta[1,15]$. Soderblom et al [12] also showed significant correlation between HA, TNF- $\alpha$ and IL- $1 \beta$ in patients with pleural effusions. However, this data was derived mainly from patients with an inflammatory disease such as rheumatoid arthritis, where parapneumonic effusions comprised a minority. In our study, we have evaluated pleura and serum levels of HA, TNF- $\alpha$ and IL- $1 \beta$ in order to investigate whether such an association could be demonstrated in a different population. Similarly to HA levels, both TNF- $\alpha$ and IL- $1 \beta$ levels were significantly higher in the pleural fluid of patients with complicated parapneumonic effusion compared to other types of effusions. However, in our study we found no significant correlation between pleural fluid levels of HA, TNF- $\alpha$ and IL- $1 \beta$. These differences between the present and former study which assessed HA in pleural effusions might be explained by differences in the populations studied. In contrast to Soderblom et al [12], we have studied mainly patients with infections where the regulation of the production of proinflammatory cytokines in the pleura is likely to be more complex and different than in inflammatory diseases such as rheumatoid arthritis.

In conclusion, our findings suggest that pleural fluid hyaluronic acid levels are increased in patients with complicated parapneumonic effusions compared to transudates or other types of exudates. HA levels in serum did not differ in different types of pleuritis and this may suggest local production of $\mathrm{HA}$ and a potential role of HA in the 
inflammatory process that characterise pleuritis. The analysis of pleural fluid hyaluronic acid levels along with classic pleural fluid biochemical markers such as $\mathrm{pH}$ may contribute to the early identification of complicated parapneumonic effusions that need to be managed more aggressively.

\section{References}

1. Wang PM, Lai-Fook SJ. Pleural tissue hyaluronan produced by postmorten ventilation in rabbits. Lung 2000; 178: $1-12$.

2. Tomida M, Kyama H, Ono T. Induction of hyaluronic acid synthetase activity in rat fifroblasts by medium change of confluent cultures. J Cell Physiol 1975; 86: 121-130.

3. Matuoka K, Namba M, Mitsui Y. Hyaluronate synthetase inhibition by normal and transformed human fibroblasts during grown reductions. J Cell Biol 1987; 104: 1105-1115.

4. Turley EA. Hyaluronan and cell locomotion. Cancer Metastasis Rev 1992; 11: 21-30.

5. Knudson CB, Knudson W. Hyaluronan-binding proteins in development, tissue homeostasis and disease. FASEB J 1993; 7: 1233-1241.

6. Atagi S, Ogawara M, Kawahara M, et al. Utility of hyaluronic Acid in pleural fluid for differential diagnosis of pleural effusions: Likelihood ratios for malignant mesothelioma. Jpn J Clin Oncol 1997; 27: 293-297.

7. Roboz J, Greaves J, Silides D, et al. Hyaluronic acid content of effusions as a diagnostic aid for malignant mesothelioma. Cancer Res 1985; 45: 1850-1854.

8. Martnsson G, Thylen A, Lindgvist U, et al. The sensitivity of hyaluronan analysis of pleural fluid from patients with malignant mesothelioma and a comparison of different methods. Cancer 1994; 73: 1406-1410.

9. Laurent TC, Franser JRE. The properties and turnover of hyaluronan. In: Functions of the proteoglycans, Ciba Foundations Symposium 124.Chichester; Wiley,1986: 9-29.

10. Dentine MA, Vernally JHJ, Hendricks S, et al. Enhanced levels of hyaluronan in lungs of patients with
COPD: relationship with lung function and local inflammation. Thorax 2005; 60: 114-119.

11. Peterson T, Frosted B, Riska H, et al. Concentration of hyaluronic acid in pleural fluid as a diagnostic of malignant mesothelioma. Chest 1988; 94: 1037-1039.

12. Soderblom T, Pettersson T, Nyberg P, et al. High pleural fluid Hyaluronic concentrations in rheumatoid arthritis. Eur Respir J 1999; 13: 519-522.

13. Light RW, Macgregor MI, Luchsinger PC, et al. Pleural effusions: the diagnostic separation of transudates and exudates. Ann Intern Med 1972; 507-513.

14. BTS and ACL criteria. Pleural empyema management. Porcel et al. Respir Med 2006.

15. Davies CW, Gleeson FV, Davies RJ. BTS guidelines for the management of pleural infection. Thorax 2003; 58 (Suppl 2): ii 18-28.

16. Antony V.B. Immunological mechanisms in pleural disease. Eur Respir J 2003; 21: 539-544.

17. Safari RC, Hour G, Liu P, et al. A role for Hyaluronic in macrophage accumulation and collagen deposition after bloodying-induced lung injury. Am J Respir Cell Mol Biol 2003; 23: 475-484.

18. Mummert ME, Mohamadzadeh M, Mummet D, et al. Development of a peptide inhibitor of Hyaluronic-mediated leukocyte trafficking. J Exp Med 2000; 192: 769779 .

19. Has call VC, Majors AK, De La Matte CA, et al. Intracellular hyaluronan: a new frontier for inflammation? Biochip Biochips Act 2004; 1673: 3-12.

20. Hiro D, Ito A, Matsuka K, et al. Hyaluronic acid is an endogenous inducer of interleukin-1 production by human monocytes and rabbit macrophages. Biochem Biophys Res Commun 1986; 140: 715-722

21. Goa KL, Benfied P. Hyaluronic acid. A review of its pharmacology and use as a surgical aid in ophthalmology, and its therapeutic potential in joint disease and wound healing. Drugs 1994; 47: 536-566.

22. West DC, Kumar S. Hyaluronan and angiogenesis. In: Evered D, Whelan J, eds. The Biology of Hyaluronan. Ciba Foundation Symposium 143. Chichester, Jonn Wiley, 1989; pp.187-201.

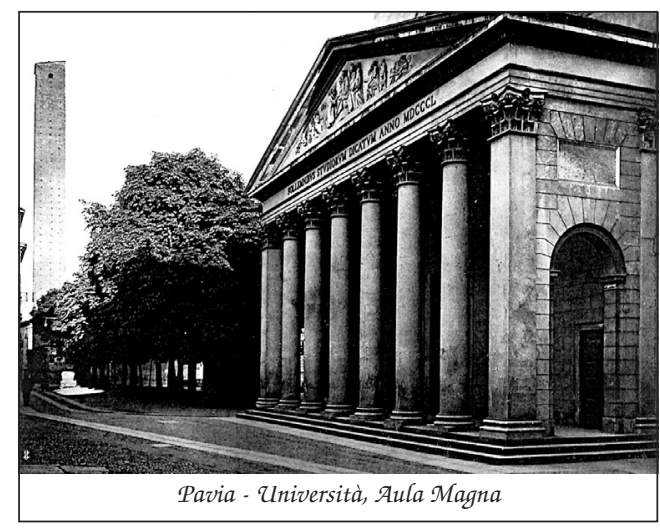

